\title{
Early left ventricular assist device-related strokes: Turn up the flow, turn down the embolism?
}

\author{
Mark Helmers, MD, and Pavan Atluri, MD
}

\footnotetext{
From the Division of Cardiovascular Surgery, Department of Surgery, University of Pennsylvania, Philadelphia, $\mathrm{Pa}$.

Disclosures: Authors have nothing to disclose with regard to commercial support.

Received for publication July 25, 2018; accepted for publication July 26, 2018; available ahead of print Sept 7, 2018.

Address for reprints: Pavan Atluri, MD, Division of Cardiovascular Surgery, Department of Surgery, Hospital of The University of Pennsylvania, 3400 Spruce St, 6 Silverstein Pavilion, Philadelphia, PA (E-mail: Pavan. Atluri@uphs.upenn.edu).

J Thorac Cardiovasc Surg 2019;157:268-9

$0022-5223 / \$ 36.00$

Copyright $($ c 2018 by The American Association for Thoracic Surgery

https://doi.org/10.1016/j.jtcvs.2018.07.081
}

Despite technical and surgical advances in continuous-flow left ventricular assist devices (LVADs), stroke remains a major complication. In the eighth annual Interagency Registry for Mechanically Assisted Circulatory Support report, ${ }^{1}$ stroke dominates as the major cause of death between 6 months and 4 years of device support. Previously identified risk factors for stroke in LVAD patients include pump thrombosis, infection, blood pressure, gastrointestinal bleeding, and excessive antithrombotic treatment. ${ }^{2-4}$ Patients are at increased risk of stroke during the early period of device support with an occurrence rate of 2.42 per 100 patient months in the first 3 months of LVAD support and 1.12 in the subsequent 9 months after device implant.

Samura and colleagues ${ }^{5}$ present a single institutional, retrospective analysis of risk factors for symptomatic stroke specific to the acute phase (first 90 days) after continuousflow LVAD implantation. Twenty-eight of 158 consecutive study patients $(18 \%)$ experienced a symptomatic stroke during the acute phase. Although age, female sex, body surface area, cardiopulmonary bypass time, and postoperative minimum cardiac output were univariate risk factors for early stroke, low cardiac output during the postoperative 12 to 24 hours was the only independent risk factor of significance on multivariate analysis (odds ratio, 0.25; 95\% confidence interval, 0.07-0.92; $P=.024)$. This association held true for both centrifugal and axial flow devices.

Patients experiencing acute phase stroke were noted to have significantly higher serum lactate dehydrogenase $(\mathrm{LDH})$ every day during the first 2 weeks following implant. Hemolysis is strongly associated with pump thrombosis and thromboembolism ${ }^{6}$ and LDH levels $>5$ times the upper limit of normal have been shown to be a very sensitive and specific biomarker of pump thrombosis. ${ }^{7}$ The authors theorize low cardiac output in the early postoperative period may result in subclinical pump thrombosis that predisposes patients to stroke. ${ }^{5}$ This hypothesis is further supported by the authors' finding of a negative correlation between serum of stroke.

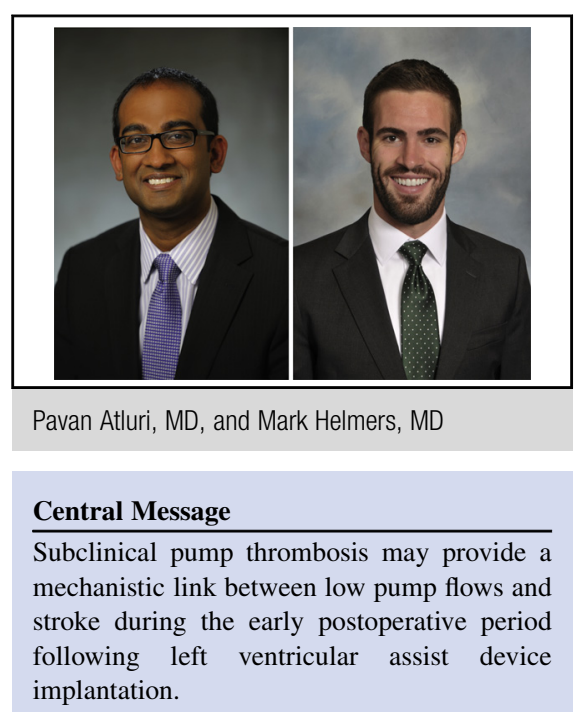

See Article page 259

LDH at 14 days and minimum cardiac output at postoperative 12 to 24 hours $(r=-0.313 ; P=.03)$.

The authors acknowledge the single institution, retrospective nature of the study, use of 5 different devices, and institutional stroke screening strategy as potential limitations of the study. ${ }^{5}$ Perhaps more troubling to the central hypothesis is the fact that 20 of 28 strokes $(71 \%$ ) were hemorrhagic in nature. Whereas hemorrhagic conversion of ischemic stroke is a potential etiology, LVAD patients are predisposed to spontaneous hemorrhagic stroke secondary to anticoagulation, acquired von Willebrand syndrome, and mycotic aneurysm. ${ }^{9}$ In these contexts, it is less clear how subclinical pump thrombosis could lead to stroke. Larger series have demonstrated a $2: 1^{10}$ or $3: 1^{11}$ predominance of ischemic strokes in LVAD patients, so the authors' theory may be more broadly applicable.

Regardless of these limitations, the authors should be commended for their contribution. Their work offers a novel mechanistic explanation for early stroke in LVAD patients and exciting implications for potential intervention. Certainly further studies are warranted to investigate the relationship between pump flows, subclinical pump thrombosis, and early stroke in this population and to determine whether targeting higher minimum cardiac outputs during the early postoperative period can decrease the incidence 


\section{References}

1. Kirklin JK, Pagani FD, Kormos RL, Stevenson LW, Blume ED, Myers SL, et al. Eighth annual INTERMACS report: special focus on framing the impact of adverse events. J Heart Lung Transplant. 2017;36:1080-6.

2. Nifong LW, Rodriguez E, Chitwood WR Jr. 540 Consecutive robotic mitral valve repairs including concomitant atrial fibrillation cryoablation. Ann Thorac Surg. 2012;94:38-42; discussion 43.

3. Harvey L, Holley C, Roy SS, Eckman P, Cogswell R, Liao K, et al. Stroke after left ventricular assist device implantation: outcomes in the continuous-flow era. Ann Thorac Surg. 2015;100:535-41.

4. Morgan JA, Brewer RJ, Nemeh HW, Gerlach B, Lanfear DE, Williams CT, et al. Stroke while on long-term left ventricular assist device support. ASAIO J. 2014; 60:284-9.

5. Samura T, Yoshioka D, Toda K, Sakaniwa R, Shimizu M, Miyagawa S, et al. Risk of stroke early after implantation of a left ventricular assist device. J Thorac Cardiovasc Surg. 2019;157:259-67.e1.

6. Cowger JA, Romano MA, Shah P, Shah N, Mehta V, Haft JW, et al. Hemolysis: a harbinger of adverse outcome after left ventricular assist device implant. J Heart Lung Transplant. 2014;33:35-43.

7. Uriel N, Morrison KA, Garan AR, Kato TS, Yuzefpolskaya M, Latif F, et al. Development of a novel echocardiography ramp test for speed optimization and diagnosis of device thrombosis in continuous-flow left ventricular assist devices: the Columbia ramp study. J Am Coll Cardiol. 2012;60:1764-75.

8. Uriel N, Pak SW, Jorde UP, Susen S, Vincentelli A, Ennezat PV, et al Acquired von Willebrand syndrome after continuous-flow mechanical device support contributes to a high prevalence of bleeding during long-term support and at the time of transplantation. J Am Coll Cardiol. 2010;56:1207-13.

9. Willey JZ, Demmer RT, Takayama H, Colombo PC, Lazar RM. Cerebrovascular disease in the era of left ventricular assist devices with continuous flow: risk factors, diagnosis, and treatment. J Heart Lung Transplant. 2014; 33:878-87.

10. Parikh NS, Cool J, Karas MG, Boehme AK, Kamel H. Stroke risk and mortality in patients with ventricular assist devices. Stroke. 2016;47:2702-6.

11. Willey JZ, Gavalas MV, Trinh PN, Yuzefpolskaya M, Reshad Garan A, Levin AP, et al. Outcomes after stroke complicating left ventricular assist device. J Heart Lung Transplant. 2016;35:1003-9. 